\title{
Derechos humanos, desarrollo local y educación en contextos de exclusión social
}

\author{
Human rights, local development and education \\ in contexts of social exclusion
}

\section{Jesús Delgado Baena* y Rocío Vela Jiménez**}

* Doctor europeo por la Universidad Pablo de Olavide de Sevilla (UPO), España. Línea de investigación derechos humanos y desarrollo local. Profesor del Departamento de Trabajo Social y Servicios Sociales y profesor estable del Máster de Derechos Humanos de la UPO.

* †malayo77@gmail.com https:/ / orcid.org/ 0000-00019206-9619

** Doctoranda y ayudante de investigación en la Universidad Loyola Andalucía. Línea de investigación en desarrollo inclusivo y sostenible. Magíster en Derechos Humanos, Interculturalidad y Desarrollo (Universidad Pablo de Olavide). Licenciada en Antropología Social y Cultural (Universidad de Sevilla).

* trveljim@hotmail.com https:// orcid.org/ 0000-00024957-385X

RECIBIDO: 30.9 .2019

ACEPTADO: 10.11.2019

\section{Resumen}

La educación es un elemento esencial para generar procesos de lucha por la dignidad en los territorios, si se la entiende como un proceso cultural y de liberación, según explicitan autores como Paulo Freire y Herrera Flores. En zonas de exclusión social, la educación presenta diferentes enfoques y vertientes, y el sistema educativo se configura de forma hegemónica en un contexto neoliberal que aplica modelos educativos homogéneos y universales. Sin embargo, como señala Freire, la educación como práctica de libertad es una construcción dinámica y de contexto que debe partir de la heterogeneidad de los territorios para generar procesos que impidan la exclusión social y humana. En este sentido, el desarrollo y la educación podrían definirse como derechos humanos, como procesos culturales emancipadores hacia la dignidad humana.

Palabras clave: educación, derechos humanos, exclusión social, desarrollo participativo.
Abstract
Education is an essential element to generate pro- cesses of struggle for human dignity in the territories, if it is understood as a cultural and liberation process, as explained by authors such as Paulo Freire and Her- rera Flores. In areas of social exclusion, education pre- sents different approaches and aspects, whereas the 
educational system is configured in a hegemonic way, within a neoliberal context based on homogeneous and universal educational models. However, as Freire points out, education as a practice of freedom is a dynamic and contextual construction that must start from the heterogeneity of the territories in order to generate processes that prevent social and human exclusion. In this sense, development and education could be defined as human rights, as emancipatory cultural processes towards human dignity.

Keywords: education, human rights, social exclusion, participatory development.

\section{Introducción}

Este artículo nace del interés por una educación como práctica de la libertad en los procesos de desarrollo local que permita crear en los individuos disposiciones críticas ante sociedades injustas para la mayoría los territorios. Para la realización de este trabajo es necesario cruzar dos elementos conceptuales: derechos humanos y desarrollo local en el marco de la educación.

El trabajo parte de las experiencias realizadas en un contexto concreto, el barrio del Polígono Sur en la ciudad de Sevilla, uno de los más pobres de España, y el impacto que tiene en el desarrollo de este la educación hegemónica. La conclusión de estas experiencias afirma que las miradas hegemónicas de los procesos educativos provienen de un modelo de desarrollo hegemónico global que entiende el desarrollo como una sola forma homogénea de generar procesos locales y afecta, por ende, a cualquier contexto mundial, incluidos los de las ciudades latinoamericanas y sus territorios en situación de exclusión social.

Este artículo no tiene una pretensión jurídica, es decir, no quiere formular un marco legal de la educación y de los derechos humanos. Estos no se presentarán como elementos normativos, sino como productos culturales y procesos de lucha por la dignidad humana, como entienden autores como Herrera Flores (2008) o Boaventura de Sousa Santos (1998).

Entender los derechos humanos como procesos de lucha permite acercarnos a ellos desde una perspectiva integral que establece la educación y el desarrollo local como elementos fundamentales para generar procesos emancipatorios en los territorios.

Así, este trabajo se iniciará con un marco teórico y conceptual en el cual se establecerá el paradigma crítico como punto de partida inicial para abordar la conceptualización de la educación desde una perspectiva hegemónica vinculada al neoliberalismo global actual. Con una mirada crítica, se planteará que el desarrollo local y la educación se inscriben en un contexto de políticas públicas sociales que a su vez tienen un marco hegemónico neoliberal global. 
Posteriormente se realizará un acercamiento a la conceptualización y a las realidades de exclusión social para visibilizar como afecta esta mirada hegemónica de la educación en el contexto educativo en estos territorios y, por ende, en sus procesos de desarrollo local.

El proceso educativo de las personas que provienen de estos ambientes sociales y familiares marginales se torna realmente una tarea complicada tanto para el propio alumnado como para el profesorado y los agentes que median entre la escuela y la comunidad.

Ello se complica aún más en un contexto en el que las desigualdades sociales afectan a las personas desde que nacen, y determinan su posición en un mundo que premia la excelencia y la competitividad. Ante ese modelo societario, los niños y niñas que no resultan rentables son confinados a continuar formando parte de la espiral de la exclusión social. La escuela podría convertirse en la llave que permita abrir caminos para su liberación.

Finalmente, se establecerán elementos alternativos al modelo hegemónico educativo en los procesos de desarrollo local de los territorios en exclusión social, vinculados a una mirada crítica y popular de la educación como la postuló Paulo Freire (1969/2009, 1970/2012,1990, 2001)

Este trabajo se propone establecer mediante una revisión bibliográfica que los procesos educativos no deben partir de una visión global del desarrollo hegemónico; por eso mismo, no pretende ser un estudio de caso particular en alguna sociedad o país, sino ofrecer un marco teórico del cual partir para poder realizar procesos de desarrollo local emancipadores a partir de la práctica educativa en los territorios en situación de exclusión social.

Las personas son un fin en sí mismo para el desarrollo local, al igual que sus necesidades, lo que pone el énfasis en la participación social. El territorio es un marco contextual, pero igualmente es el protagonista del proceso de desarrollo local. Las capacidades humanas se tornan imprescindibles para protagonizar dichos procesos, y es ahí donde la educación aparece como un elemento sustancial para el desarrollo local.

$\mathrm{Si}$ afirmamos que la finalidad del desarrollo local son los seres humanos como fines del desarrollo, entonces hay que poner las necesidades de las personas como el principal objetivo de estos procesos. Por lo tanto, al poner el foco en contextos de exclusión social, se podrá ver como estos espacios requieren de una dinamización social para generar procesos de transformación. En este sentido, la educación es un elemento esencial para establecer espacios de lucha por la dignidad humana.

Así, se expondrá en este trabajo la concepción de la educación como un medio facilitador de dignidad humana y cómo esta se desvirtúa en los contextos de exclusión social, donde no cumple una función emancipadora sino que perpetúa la situación de exclusión. 


\section{Educación y desarrollo hegemónico}

El Comité de Derechos Económicos, Sociales y Culturales (CESCR) de las Naciones Unidas ha formulado el alcance del derecho a la educación en la observación general 13 (Organización de las Naciones Unidas [ONU], 2000):

La educación es un derecho humano intrínseco y un medio indispensable de realizar otros derechos humanos. Como derecho del ámbito de la autonomía de la persona, la educación es el principal medio que permite a adultos y menores marginados económica y socialmente salir de la pobreza y participar plenamente en sus comunidades. La educación desempeña un papel decisivo en la emancipación de la mujer, la protección de los niños contra la explotación laboral, el trabajo peligroso y la explotación sexual, la promoción de los derechos humanos y la democracia, la protección del medio ambiente y el control del crecimiento demográfico. Está cada vez más aceptada la idea de que la educación es una de las mejores inversiones financieras que los Estados pueden hacer, pero su importancia no es únicamente práctica, pues disponer de una mente instruida, inteligente y activa, con libertad y amplitud de pensamiento, es uno de los placeres y recompensas de la existencia humana.

Este trabajo no pretende llevar a cabo un análisis normativo de los derechos humanos en el ámbito educativo. Por eso, para hablar de derechos humanos desde un paradigma crítico, se adopta la definición del profesor Herrera Flores (2008):

Los derechos humanos son el resultado de luchas sociales y colectivas que tienden a la construcción de espacios sociales, económicos, políticos y jurídicos que permitan el empoderamiento de todas y todos para poder luchar plural y diferenciadamente por una vida digna de ser vivida.

Esta es la idea base sobre la que se construye el presente trabajo: la necesidad de establecer vínculos entre los derechos humanos, el desarrollo local y la educación, con un paradigma crítico, que permite ver los derechos humanos como aquellos que deben ser resultado de luchas sociales que empujan a los territorios a emanciparse.

Pero esta idea se transmite también desde una perspectiva local, entendiendo la necesidad de los derechos humanos como procesos territoriales que rompen con una idea hegemónica y universalista, como dice Boaventura de Sousa Santos (1998): 
Los derechos humanos radican en que pueden ser concebidos o bien como una forma de localismo globalizado o como una forma de cosmopolitanismo o, en otras palabras, como una globalización desde arriba o desde abajo.

Desde esta perspectiva se entiende cómo se puede establecer la educación en un marco de procesos de lucha por la dignidad en un territorio, y como estos procesos forman parte del desarrollo local.

Para entender el desarrollo local se parte de la conceptualización del profesor Dubois:

[...] una dinámica compleja, sistémica, en la que se articulan las restricciones y potencialidades económicas, culturales, políticas y sociales de cada territorio en la consecución del bienestar. (Dubois y Del Río, 2014)

Esta conceptualización se vincula a la que establecen los profesores De Sousa Santos (1998) y Herrera Flores (2008) con respecto a los derechos humanos, ya que muestra la integralidad del concepto y su propia complejidad, al entender el bienestar también como el resultado de los propios procesos de desarrollo.

$\mathrm{Al}$ situarnos en el contexto uruguayo y latinoamericano, podemos partir de las ideas del profesor Gallicchio (2004) para plantear diferentes elementos que nos llevan a entender el desarrollo local como «el ámbito de territorialización de las políticas». Es decir, en el contexto latinoamericano el desarrollo local nace porque los Estados han sido muy centralizados y nunca entendieron el desarrollo local como un proceso territorial y local. Actualmente esto ha cambiado y los Estados centrales entienden que las políticas públicas deben pasar por la descentralización y la autogestión, y que la participación ciudadana significa la apropiación de recursos tratados y discutidos por los propios territorios. Esto, por lo tanto, afecta a la hora de establecer en los países modelos educativos que garanticen políticas públicas y generen marcos y leyes de educación.

Dentro de estos procesos territoriales la educación forma parte de la integralidad de los procesos de desarrollo local en el marco de los derechos humanos desde un paradigma crítico; es decir, para los estudios de desarrollo local, la educación y su institucionalización en los territorios vienen a conformar uno de los espacios más importantes a la hora de crear un tipo de ciudadanía funcional para el sistema dominante, esto es, el sistema educativo.

Desde la antropología, la educación engloba toda la enseñanza, oficial o no, cuyo resultado es la adquisición y transmisión de cultura por el individuo, la formación de su personalidad y su socialización. Con ello, pues, se tiende a la acomodación o adaptación del sujeto para la vida en sociedad. (Bouché, 2004, p. 21) 
Durkheim (trad. 1975) fue uno de los primeros autores en desarrollar la idea de educación como institución social, cuyo fin cambia con el tipo de sociedad e incluso con la clase o el grupo social al que pertenece el educando. Cada sociedad crea un tipo ideal de individuo. La misión de la educación es suscitar en los niños y niñas cierto número de estados físicos y mentales que la sociedad a la que pertenecen considera. Es la sociedad en su conjunto la que determina el ideal que la educación realiza, configurando una homogeneidad entre los individuos que la educación perpetúa y refuerza. La educación tiene como fin formar el ser social de los sujetos (Durkheim, trad. 1975, pp. 52-54).

La ideología neoliberal en las sociedades modernas va a encontrar en la educación como institución uno de los pilares sobre los que perpetuarse. Lugar clave para dicha tarea es el sistema escolar actual.

Pero para entender el neoliberalismo es importante deconstruir el concepto. Para Harvey (2007):

El neoliberalismo es, ante todo, una teoría de prácticas político-económicas que afirma que la mejor manera de promover el bienestar del ser humano consiste en no restringir el libre desarrollo de las capacidades y de las libertades empresariales del individuo dentro de un marco institucional caracterizado por derechos de propiedad privada fuertes, mercados libres y libertad de comercio. El papel del Estado es crear y preservar el marco institucional apropiado para el desarrollo de estas prácticas.

Pero para entender cómo afecta el neoliberalismo a los propios procesos de desarrollo local, el profesor Héctor Samour (1994) alude a elementos más vinculados a la propia ideología neoliberal y afirma:

a. La historia no tiene un sentido o un fin determinado, pero consiste en el desarrollo y la lucha entre la sociedad abierta y cerrada (Popper citado por Samour, 1994). El modelo neoliberal nace porque la historia es completamente casual; no existe la racionalidad.

b. La sociedad capitalista contemporánea es la mejor de cuantas han existido y es insuperable. Es decir, el llamado fin de la historia llegó con la caída del bloque soviético, lo que demostró que el capitalismo es el único modelo exitoso.

c. El mercado es el único ordenamiento económico racional. No es necesaria la intervención del Estado, ya que el modelo neoliberal y capitalista se autorregula y es equilibrado.

d. El neoliberalismo no significa una desestatización de la vida social, como lo afirman sus ideólogos, sino una reestructuración de los fines del Estado por la 
cual se minimizan las funciones sociales. Hay que criticar la burocratización del Estado como elemento que entorpece el Estado.

e. La democracia es solo un método político y debe adecuarse al orden de las tradiciones y normas sociales. Las personas deben adaptarse al modelo capitalista, rompiendo así con procesos locales y permitiendo siempre el consumo de la producción global.

f. Los neoliberales sustituyen la soberanía popular por la concepción de la soberanía de la ley, identificando la democracia y el liberalismo político con este principio. Se debe cuidar el modelo productivo capitalista.

Desde esta perspectiva, es fácil entender que en cada territorio, en un mundo globalizado, el sistema escolar, con un posicionamiento hegemónico neoliberal, conforma uno de los lugares donde se fabrican personas, donde se crean las formas de pensar, las formas de actuar en relación directa con otros sistemas, como el familiar, como lugar de socialización.

No se puede estudiar el funcionamiento de un territorio o sociedad sin estudiar el sistema educativo. El sistema escolar es el lugar donde se reproducen las estructuras sociales, donde el neoliberalismo se perpetúa como ideología hegemónica, dentro de una lógica de desarrollo global neoliberal.

Por tanto, el sistema escolar es clave para entender las sociedades modernas, donde los grupos sociales garantizan su continuidad. Es en esta relación de desigualdad donde el sistema neoliberal legitima el funcionamiento del sistema educativo como máquina reproductora de su modelo hegemónico de desarrollo, puesto que, a partir de las diferencias de clase, realiza toda una criba ideológica, que es también económica, con base en una pedagogía excluyente que reproduce una sociedad desigual, de lo que resulta una relación directa entre el origen social de los alumnos y alumnas y los resultados académicos.

La puesta del sistema educativo al servicio de la ideología dominante define claramente la mercantilización de la educación. En esta tarea reproductora que lleva a cabo el sistema educativo se puede ver también la desigualdad que se establece entre el que educa y el educando. La jerarquización de las relaciones que caracteriza al sistema social también se inscribe en el sistema escolar. Si existe un fracaso en la tarea educativa, la responsabilidad no se considera del sistema en su conjunto, sino que se individualiza en el estudiante.

Legitimando el orden establecido, naturalizando esta acción, el neoliberalismo entendido como la plena apertura y liberalización de la economía, el libre mercado, evitando el gasto y el intervencionismo público- encuentra en la escuela un lugar donde producir sujetos que sean funcionales para su hegemonía. 
Las ideologías no constituyen solo conjuntos globales de intereses, cosas «impuestas» por un grupo sobre otro; se encuentran incorporadas a los significados y prácticas de nuestro sentido común. (Apple, 1997, p. 12)

La ideología es vista como algo que, de alguna manera, hace sentir sin demasiado esfuerzo sus efectos sobre la gente en la economía, la política, la cultura, la educación y en su hogar. Simplemente está allí. El sentido común de la gente se vuelve sentido común «naturalmente» mientras transcurren sus vidas diarias, preestructuradas por su posición de clase (Apple, 1997, p. 79).

Las instituciones sociales van a ser inscritas bajo los principios neoliberales de competitividad, acumulación, rentabilidad, fragmentación, y la institución escolar es uno de los lugares estratégicos que exportan los productos acabados con estos ingredientes secretos. «La cultura es transformada en mercancía en las escuelas» (Apple, 1997, p. 25).

El sistema educativo también va a verse afectado hasta el punto de que ya se puede hablar de que está siendo sometido a casi las mismas reglas que rigen en la esfera de la producción y el comercio. (Torres, 2001, p. 28)

La homogeneización como estrategia neoliberal es determinante a la hora de su reproducción como sistema cultural. Globalizar los principios sustentadores de esta ideología en el todo social viene a conformarlo como cultura hegemónica, impregnando todas las esferas de la sociedad. «La idea esencial es que la clase dominante dará a sus ideas una forma de universalidad, y las presentará como las únicas racionales y universalmente válidas» (Apple, 1997, p. 45).

Así el capitalismo se conforma no solo como sistema económico, sino como sistema cultural que se cuela por todos los ámbitos del desarrollo de los territorios, entre ellos el ámbito educativo.

Esta definición de la educación como vertedora de conocimientos (predeterminados) en los alumnos nos lleva directamente al concepto de educación bancaria de Freire, aquel en el que la educación es entendida como un proceso en el cual el alumno debe contener una serie de conocimientos preestablecidos.

La narración, cuyo sujeto es el educador, conduce a los educandos a la memorización mecánica del contenido narrado. Cuanto más vaya llenando los recipientes con sus «depósitos», tanto mejor educador será. Cuanto más se dejan «llenar» dócilmente, tanto mejor educandos serán. De este modo, la educación se transforma en un acto de depositar en el cual los educandos son los depositarios y el educador quien deposita. Tal es la concepción «bancaria» de la educación, en que el único 
margen de acción que se ofrece a los educandos es el de recibir los depósitos, guardarlos y archivarlos. Margen que solo les permite ser coleccionistas o carpetas de cosas que archivan. En el fondo, los grandes archivados de esta práctica equivocada de la educación son los propios hombres. (Freire, 1970/ 2012, p. 62)

La idiosincrasia de los mercados capitalistas que impregna el sistema educativo actualmente se asienta sobre los siguientes rasgos, como señala Jurjo Torres (2001, pp. 218-220):

a. La producción de mercancías o artículos de consumo.

b. Intercambio cuantitativo entre quienes producen y quienes consumen.

c. Relaciones de competitividad y rivalidad.

d. Crear en las personas una «subjetividad de mercado»: construir personalidades con deseo de consumir y enriquecerse sin límites.

e. Así, «la diferencia entre fabricar automóviles, lavadoras y televisores y formar personas sería mínima».

La globalización capitalista ha acrecentado las desigualdades y así ha contribuido a la sociedad $20 / 80$, donde el $20 \%$ de la población mundial concentra la riqueza, vive en la opulencia, mientras el $80 \%$ lo hace a duras penas.

La usurpación de la institución escolar por la ideología neoliberal no puede quedar como el fin de la historia de la educación. Rechazar este fin de la historia nos lleva a la «apertura de procesos de lucha por la dignidad humana» (Herrera Flores, 2008, p. 15), en los que la educación se convierte en un medio al que acceder para que la vida sea digna de ser vivida.

Los excluidos por un sistema injusto encuentran en la educación el espacio donde iniciar procesos para ser libres.

El sistema educativo es en realidad y fue fruto de luchas sociales muy importantes llevadas a cabo por quienes sufrían las más graves injusticias, como una de las estrategias primordiales para lograr mayores cotas de justicia e igualdad. Olvidar la historia de las luchas encaminadas a lograr que la educación fuera un servicio público, gratuito y obligatorio facilita que se lleguen a desvirtuar las finalidades del trabajo escolar; que se piense que tiene únicamente el objetivo de capacitar para un puesto de trabajo. Preparar una ciudadanía con capacidades, destrezas, valores y conocimientos para llevar a cabo esta tarea obliga a quienes tienen responsabilidades en el sistema educativo a mirar mucho más allá de las necesidades que manifiestan los propietarios y propietarias de las fábricas y negocios privados. (Torres, 2001, p. 222) 
Situarnos en las periferias parece un lugar idóneo para visibilizar la lógica de un sistema injusto, necrófilo, que legitima la miseria de muchos a costa de la codicia de unos pocos. Es en esa periferia, en contextos de exclusión social, donde queremos iniciar la búsqueda de la educación problematizadora de la que Freire (1990) nos hablaba, que viene a encajar en la concepción de lucha histórica, contextualizada, de los derechos humanos como procesos que nos planteaba Herrera Flores. «La historia de los grupos marginados y oprimidos por esos procesos de división del hacer humano es la historia del esfuerzo por llevar adelante prácticas y dinámicas sociales de lucha contra [ellos]» (2008, p. 27).

La educación problematizadora no es una fijación reaccionaria, es futuridad revolucionaria. De ahí que sea profética y, como tal, esperanzada. De ahí que corresponda a la condición de hombres como seres históricos y a su historicidad. De ahí que se identifique con ellos como seres más allá de sí mismos - como «proyectos»—, como seres que caminan hacia adelante, que miran al frente; como seres a quienes la inmovilidad amenaza de muerte; para quienes el mirar hacia atrás no debe ser una forma nostálgica de querer volver sino una mejor manera de conocer lo que está siendo, para construir mejor el futuro. (Freire, 1970/ 2012, p. 77)

\section{Educación en contextos de exclusión social}

Es necesario acercarnos a los contextos donde la lógica de la desigualdad se instala con mayor ferocidad. Por eso es en los contextos de exclusión social donde queremos iniciar la comprensión del derecho humano a la educación, porque allí este, lejos de pertenecer a la ciudadanía, se pone al servicio de la ideología neoliberal. «Los derechos humanos hay que entenderlos y ponerlos en práctica en sus contextos históricos concretos» (Herrera Flores, 2008, p. 29).

Empecemos por definir el concepto de exclusión social. Para ello vamos a utilizar como referente a Tezanos (1999), quien señala que este concepto nos remite a una imagen dual de la sociedad, con un sector integrado y otro excluido.

El significado de «exclusión social» se define en sentido negativo, en términos de aquello de lo que se carece. Por lo tanto, su comprensión cabal solo es posible en función de la otra parte de la polaridad conceptual de la que forma parte, de su referente alternativo: la idea de «inclusión» 0 «integración» social. Es decir, la expresión «exclusión social» implica, en su raíz, una cierta imagen dual de la sociedad, en la que existe un sector «integrado» y otro «excluido». En consecuencia, el estudio de la lógica de la exclusión social nos remite en primer lugar a todo aquello 
que en un momento dado determina la ubicación de los individuos y los grupos sociales a uno y otro lado de la línea que enmarca la inclusión y la exclusión. (Tezanos, 1999, p. 12)

Es una inclusión o exclusión que viene a determinar quién puede participar del goce de una vida digna, disfrutar de los derechos fundamentales que se relacionan con su bienestar. La noción de exclusión conlleva en sí misma una idea de regresión, de proceso que conduce a quitar algo que se había conseguido, o a lo que se tiene o tenía derecho.

En una sociedad como la actual, marcada por una crisis en la que cada vez es más difícil acceder a bienes básicos como vivienda, empleo (digno), a una educación de calidad, etc., las políticas neoliberales que practican los estados deja en entredicho la noción de ciudadanía social, donde, insensible a los factores sociales, la solidaridad queda arrinconada (Autés, 2004). «Se está configurando un contexto propicio para la acentuación de la "dualización social" de la ciudadanía, con importantes riesgos de desigualdades sociales y en el que emerge con fuerza la exclusión social». (Tezanos, 2001, p. 168)

En la búsqueda de causas que lleven a situaciones de exclusión social, una de las claves es tener o no un trabajo. Aunque existen más factores, esta es una de las razonas por las que determinadas personas se ven excluidas del disfrute de una ciudadanía plena.

Cuando se abordan procesos de desarrollo local, se explicita la relación directa que existe entre el nivel formativo y el empleo, por lo que la educación - el acceso y el disfrute de esta- es condición necesaria para acceder al empleo. Hay que tener en cuenta que un empleo no es definitorio de condiciones sociales dignas, puesto que actualmente la precarización laboral incide también en la exclusión social.Como señala David Harvey (2007), «estamos volviendo a las condiciones de trabajo del siglo XIX; es a lo que apunta el proyecto neoliberal».

El nivel de formación incide como condición previa para el acceso al empleo en las sociedades modernas, influyendo en los procesos que pueden llevar a la exclusión social.

La formación recibida en el sistema educativo otorga competencias que facilitan la integración socio-laboral pero también, de forma paralela, contribuye al desarrollo personal, social y emocional de los individuos. Sin embargo, en este espacio formativo concurren situaciones que actúan como condicionantes o determinantes de los procesos de exclusión escolar y social, que dificultan o merman la integración social. Factores tales como los bajos niveles formativos, el analfabetismo, el no dominio de idiomas extranjeros, el desconocimiento de la lengua, el 
absentismo prolongado, el abandono del sistema educativo sin la obtención de la titulación básica, los índices de fracaso escolar, de vulnerabilidad en el ámbito escolar, social y laboral. Por tanto, la exclusión social también exige prestar atención a las políticas de educación y formación. (Jiménez, Luengo y Taberner, 2009, p. 26)

El sistema económico en los últimos dos siglos ha ido configurando un sistema educativo que responda a las exigencias de la economía de mercado, que caracteriza al capitalismo en el marco de la globalización. La ideología neoliberal, como hemos expuesto, necesita crear en los ciudadanos una identidad que responda a tales exigencias. La meritocracia viene a definir el nuevo paradigma educativo tras la Segunda Guerra Mundial, por el que se busca el potencial del sujeto para aprender, a través de una selección de los mejores (Jiménez, Luengo y Taberner, 2009). «La acumulación de capital que es típica del mercado capitalista tendría su equivalente en el sistema escolar en la acumulación de títulos» (Torres, 2001, p. 221). Este nuevo paradigma de acumulación de títulos pone en el individuo toda la carga del éxito escolar, de su éxito vital, de su situación de inclusión o exclusión social.

Siguiendo a Bourdieu (2001), volvemos a plantear que la ideología dominante busca que el sistema educativo sea funcional al mercado, para lo que marca en las prácticas escolares, y en las opiniones sobre esas prácticas, el esfuerzo como justificación ética del mérito.

Aparece una nueva estrategia de exclusión social: el fracaso escolar, que, lejos de tornarse como un problema del sistema educativo en su conjunto, atribuye al sujeto, a su falta de motivación o habilidades, la culpa de no conseguir el éxito escolar que redundaría en su éxito social.

El fracaso escolar se explicará ahora por la falta de motivación del alumno que no ha querido o no ha sabido aprovechar los recursos que el sistema le ha ofrecido, apareciendo una nueva estrategia de exclusión que tratará de convencer al propio sujeto, por mediación de los propios profesores, de su propio fracaso, persuadiéndoles de que no poseen las características intelectuales requeridas, o que no demuestran las habilidades o competencias previamente establecidas, estrategia que, por otra parte, exime de toda responsabilidad al sistema educativo de dicho fracaso. (Jiménez, Luengo y Taberner, 2009, p. 30)

El concepto de capital cultural de Bourdieu (2001) nos remite a la hegemonía de la clase dominante y a legitimación del orden social establecido. Los alumnos que no asimilan los contenidos, las aptitudes, las titulaciones, la ideología dominante quedarían excluidos y, en la lógica que se nos presenta, autoexcluidos, «porque el sujeto tiene que reconocer erróneamente, al naturalizarse el conocimiento, la primacía de dicha cultura» 
(Bourdieu, 2001). Es la violencia simbólica en la escuela, de la que Bourdieu nos habla cuando se refiere al capital cultural como filtro, que permite la reproducción de la ideología dominante.

La excelencia neoliberal aboca a los alumnos que no cumplan con las exigencias del sistema escolar, que no rindan, que no asistan al centro, que presenten problemas de conducta, etcétera, a la expulsión de este, construyendo así una nueva forma de rechazo, de exclusión educativa y por tanto social. La vinculación existente entre los ámbitos formativos, económicos y laborales se considera pues fundamental para la integración social de la ciudadanía. «La exclusión escolar va de la mano de formas previas de exclusión social» (Escudero, 2002, p. 139)

De este modo, el desarrollo del derecho a la educación es clave para la integración social de los individuos. El fracaso escolar resulta de un proceso en el que al individuo no se lo puede ver aislado de las estructuras sociales en las que se inscribe. Es un proceso en el que operan diversos factores que lo llevan a la exclusión social. Esta mirada exculpa al alumnado del fracaso escolar que le es atribuido, y en cambio pone el acento en los procesos en los que el individuo se hace, por lo que se contrapone a una visión cuantitativa de resultados académicos, de posesión.

Por ello es necesario ampliar la visión, no focalizar individualmente las causas de un fracaso que no es consustancial al sujeto. En contextos familiares y sociales de exclusión social, los niños y las niñas cuentan con escaso apoyo tanto para el éxito escolar como social. La exclusión social se reproduce, y favorece la exclusión escolar; la exclusión educativa de los padres también se reproduce en los hijos e hijas y, a su vez, el fracaso escolar hace más difícil la inserción social a través de un trabajo estable. Hay, pues una correlación mutua con carga causal, una periferia social que empuja hacia una periferia escolar y a la inversa. (López y Taberner, 2009, pp. 235-337)

En los territorios específicos en los que se inscribe la escuela, esta debe articular la construcción de su identidad a partir de la exigencia de una doble relación.

Cada escuela construye su identidad articulando contradictoriamente el mandato de transmitir la cultura y la relación con su medio sociocultural inmediato. Se trata de una construcción compleja y contradictoria, ya que la escuela forma parte del barrio, participa de su escenario y de la construcción social de la identidad; pero a la vez posee el mandato de transmitir la cultura hegemónica, mandato consolidado por un imaginario escolar instituido. (Berger, 2006, p. 2) 
En contextos de exclusión social las escuelas deben desplegar toda una creatividad práctica a la hora de contrarrestar las dinámicas excluyentes que afectan a la comunidad y, por tanto, a los alumnos y alumnas.

Existe así en la escuela una tensión entre el imperativo de la ideología dominante y las resistencias a esta. «Las escuelas públicas también reflejan demandas sociales» (Apple, 1997, p. 193).

La escuela puede convertirse en un espacio de lucha contrahegemónica en la articulación de esa tensión entre el sistema capitalista y la sociedad. «El sistema educacional y sus políticas y prácticas internas han sido de hecho construidos a partir de conflictos» (Apple, p. 192).

Las instituciones escolares no funcionan siempre en un sentido reproductor, sino que existe una cierta autonomía que permite posibilidades de acción contrahegemónica. (Torres, 2001, p. 232)

La educación debe partir de cuestiones que generen en los alumnos y alumnas una motivación hacia el aprendizaje. En contextos de exclusión social esto se hace aún más necesario, puesto que la no respuesta del sistema educativo a las necesidades de los jóvenes incide de forma directa en la desvalorización que hacen estos de la educación (Apple, 1997). «Los estudiantes no solo reproducen las ideologías dominantes, sino que al mismo tiempo también actúan contra ellas» (Apple, 1997, p. 34)

El sistema educativo enmarcado en procesos de desarrollo local debe transformar su práctica en cada contexto concreto, de forma que propicie espacios en los que alumnos y alumnas encuentren un sentido al hecho educativo, donde no se practique la educación bancaria de la que Freire (1970/2012) nos habla. Se apuesta así por un «proyecto antidiscriminación», por «centros escolares generadores de sueños y no de sueño» (Torres, 2001, p. 214):

Los sistemas educativos tienen entre sus finalidades más idiosincrásicas, la de mediar en la comprensión del mundo en el que se vive, ello obliga a que alumnas y alumnos desarrollen capacidades que les permitan elaborar juicios sobre lo que acontece a su alrededor. La motivación por aprender está claramente relacionada con la significatividad de lo que se trabaja. En buena lógica, si las informaciones que alumnos y alumnas tienen que estudiar son aquellas que también a ellos les preocupan, estarán más interesados en tratar de entenderlas y juzgar su valor. (Torres, 2001, p. 211)

La prevención cobra importancia como forma de contrarrestar las situaciones que abocan a la exclusión social de niños y niñas. Muchos terminan cometiendo delitos por 
no haber cumplido con los estándares que marca el sistema educativo. «Cuanto más tempranamente se detecten y se pongan medios para el reenganche escolar, más fácil será evitar que se perpetren» (Jiménez, Luengo y Taberner, 2009, p. 39).

En la tarea, en el «potencial de los profesores y profesoras como agentes de transformación social, como activistas sociales» (Torres, 2001, p. 232) es donde adquiere especial relevancia el trabajo cooperativo entre la escuela y los movimientos sociales.

Es a partir de la educación entendida como un proceso, en la que confluyen diversos factores, que adquiere también relevancia la acción social.

La acción educativa, como trabajo cultural, social, ético y político, requiere la participación de los ciudadanos y ciudadanas, de manera especial, a través de las organizaciones en las que se agrupan. (Torres, 2001, p. 235)

Por tanto, en la tarea de prevención de las causas que llevan a un sujeto a ser excluido del sistema social en el que se inscribe, del proceso que lo llevaría a un fracaso escolar que acabaría convirtiéndolo en un sujeto social excluido, adquiere relevancia, entre otras muchos espacios (como la familia, la comunidad), la intervención social que realizan diferentes profesionales en ella implicados: trabajadores/ as sociales, educadores/ as sociales, psicólogos/ as, etcétera.

El objeto de esta intervención social es el ser humano (individual o colectivo) en interacción con el medio social en el que vive, donde pueden producirse situaciones que dificultan a los sujetos el acceso a los medios que les faciliten una vida digna. Esta tarea nos remite directamente a la teoría crítica de los derechos humanos:

Los derechos humanos, más que derechos «propiamente dichos» son procesos, es decir, el resultado, siempre provisional, de las luchas que los seres humanos ponen en práctica para poder acceder a los bienes necesarios para la vida. (Herrera Flores, 2008, p. 22)

Resulta imprescindible la intervención social vinculada a la educación, para iniciar procesos que lleven a su consecución como derecho humano.

En un territorio en el que las desigualdades inciden de forma determinante en la vida de los individuos, donde la ideología neoliberal traba con fuerza las posibilidades de salida de la exclusión social, resulta necesaria una cooperación entre todos los agentes implicados en los procesos de desarrollo local para iniciar el acceso a una vida que merezca la pena ser vivida. En dichos contextos, la educación, basada en la resistencia al modelo hegemónico, se alza como espacio emancipador en la creación de un mundo más igualitario y justo, y en este espacio los profesionales de la intervención social 
adquieren un papel propiciador del cambio social, en la tarea de visibilizar e iniciar caminos que transformen la realidad social opresora.

El trabajador social que opta por el cambio lucha por revelar la realidad. Trabajo con, nunca sobre personas, a las que considera sujetos de la acción, nunca objetos 0 incidencias. Sabe perfectamente que todos los intentos de transformar radicalmente la sociedad exigen una organización consciente de los oprimidos, y que esto a su vez requiere una vanguardia lúcida. Si bien esta vanguardia no puede adjudicarse derechos de «propiedad» sobre los demás, tampoco puede ser totalmente pasiva. Deberíamos ser conscientes de qué se puede hacer en un determinado momento, puesto que hacemos lo que podemos y no lo que querríamos hacer. (Freire, 2001, p. 62)

Utilizando el contexto uruguayo como representativo en América Latina, citando al profesor Martinis (2006), los niños y niñas que forman parte de los espacios territoriales marginales se conciben como niños y niñas diferentes:

Es claro que el niño carente es concebido como un desigual, un otro ubicado en un peldaño social y cultural inferior. Su única esperanza de poder ser visualizado, algún día, como un igual pasa por el acceso a una propuesta educativa que, tomando nota de su situación de desigualdad, pueda volverlo, transmutarlo, en un igual.

Tal y como señala Martinis, citando a la Administración Nacional de Educación Pública (ANEP), en el contexto uruguayo estos «menores carentes» no cuentan con el espacio educativo adecuado (ANEP, citado por Martinis, 2006):

Este modelo de organización escolar, que demostró ser a lo largo de este siglo una herramienta sumamente exitosa para alcanzar y consolidar la integración social y la equidad, no permite afrontar en la actualidad tres urgencias que jalonan al sistema educativo: en primer término, la asunción de la educación como un componente vertebral de las políticas sociales, estructuradas sobre la noción de integralidad; en segundo lugar, la incorporación de programas que atiendan los aspectos más acuciantes vinculados a la salud y la alimentación de los niños; finalmente, la extensión del horario de clase como una de las estrategias medulares en la redefinición del proceso educativo. Asimismo, la constatación de los elevados niveles de repetición en los primeros grados escolares - fundamentalmente, en el primer año, situación que se ha mantenido incambiada en los últimos 10 años- subraya, aún más, la necesidad de ajustar el rol y la estructura institucional, docente, pedagógica, curricular y comunitaria de las escuelas. La repetición en las escuelas 
públicas está asociada a una alta inasistencia, al bajo nivel educativo de la madre y a las carencias socioeconómicas de los hogares (medidas a través del hacinamiento). (ANEP, 2000, p. 125)

El sistema educativo como mecanismo de reproducción social en un modelo neoliberal globalizado produce también en los barrios marginales de América Latina procesos que no permiten a los niños y niñas de estos barrios emanciparse y conquistar elementos de dignidad humana.

\section{Hacia una educación liberadora en los territorios}

La lógica de concentración de riqueza y acumulación impregna cualquier ámbito de la sociedad. Resulta, pues, necesario iniciar caminos que tiendan a colarse por las rendijas del sistema, para así promover cambios sociales que redunden en mayores cotas de igualdad y justicia que conduzcan a un verdadero desarrollo humano local. Es en la perspectiva del pensamiento crítico de los derechos humanos, vistos como el fortalecimiento de individuos, grupos y organizaciones, donde queremos situarnos para visibilizar planteamientos que nos lleven a la transformación social. Nos situaremos en las periferias. «La visión compleja de los derechos humanos apuesta por situarnos en la periferia. Centro solo hay uno. Periferias hay muchas» (Herrera Flores, 2008, p. 145).

El paradigma crítico nos da la clave a la hora de tratar la cuestión de los derechos humanos en el mundo contemporáneo. Se trata de superar los problemas que en una época «de exclusión generalizada, donde no cuentan las personas sino la rentabilidad» (Herrera Flores, p. 140), se excluyen voces que tienen que decir, expresar, aportar en la creación de las condiciones sociales, económicas y culturales que permitan y potencien la lucha por la dignidad mediante el diálogo y la convivencia de todos aquellos apartados del proceso de construcción de hegemonía.

Esta concepción de los derechos humanos pone en valor tanto a los sujetos como los procesos y acciones que se llevan a cabo en la consecución de los derechos sociales, en contraposición a la teoría tradicional de los derechos humanos, que define universalmente un acceso normativo a los derechos entendidos de forma naturalizada. El acceso a los derechos humanos no es más que el acceso a los medios necesarios para vivir con dignidad.

Es aquí donde encontramos la necesidad de una educación que promueva la lucha por condiciones de vida digna en la consecución de derechos que la legitimen, la creación de espacios donde los excluidos, los oprimidos puedan alzar la voz. Esto nos lleva directamente a la Educación como práctica de la libertad de Paulo Freire (1969/2009) y a su Pedagogía del oprimido (1970/ 2012). 
La «Pedagogía del Oprimido», aquella que debe ser elaborada con él y no para él, en tanto hombres o pueblos en la lucha permanente de recuperación de su humanidad. Pedagogía que haga de la opresión y sus causas el objeto de reflexión de los oprimidos, de lo que resultará el compromiso necesario para su lucha por la liberación, en la cual esta pedagogía se hará y rehará. (Freire, 1970/ 2012, p. 33)

Pero ¿cómo llevar a cabo dicha tarea pedagógica, cómo iniciar el camino que lleve a esta práctica liberadora? Como señala Freire:

El gran problema radica en cómo podrán los oprimidos, como seres duales, inauténticos, que «alojan» al opresor en sí, participar en la elaboración de la pedagogía para su liberación. Solo en la medida en que se descubra «alojando» al opresor podrán contribuir a la construcción de su pedagogía liberadora. (Freire, 1970/2012, p. 34)

Por tanto, en la medida en que los sujetos sean conscientes de la realidad opresora, de la situación no naturalizada de exclusión, de desigualdad, de vivir bajo un sistema injusto, podrán comenzar, desde la indignación, a transitar caminos que los liberen de esta situación. Es en la concienciación de los propios sujetos donde encontramos la puerta de entrada hacia otra realidad social más justa.

La pedagogía del oprimido, como pedagogía humanista y liberadora, tendrá, pues, dos momentos distintos, aunque interrelacionados. El primero, en el cual los oprimidos van desvelando el mundo de la opresión y se van comprometiendo, en la praxis, con su transformación, y el segundo, en que, una vez transformada la realidad opresora, esta pedagogía deja de ser del oprimido y pasa a ser la pedagogía de los hombres en proceso de permanente liberación. En cualquiera de estos momentos, será siempre la acción profunda a través de la cual se enfrentará, culturalmente, la cultura de la dominación. En el primer momento, mediante el cambio de percepción del mundo opresor por parte de los oprimidos y, en el segundo, por la expulsión de los mitos creados y desarrollados en la estructura opresora. (Freire, 1970/2012, p. 43)

En un sistema educativo como el actual, donde la ideología neoliberal va conformando individuos que respondan a sus intereses, donde la educación que se practica, lejos de humanizar al individuo y crear condiciones para su libertad, lo que pretende es conformarlo como un producto, dentro una relación que invisibiliza el poder dominante haciéndolo incuestionable, es donde «la educación refleja la estructura de poder» (Freire, 1970/ 2012, p. 66) y, por tanto, la práctica educativa se torna dificultosa para 
desarrollar una actitud dialógica. Por ello es necesario, como señala Freire, una pedagogía problematizadora. «Si pretendemos la liberación de los hombres. no podemos empezar por alienarlos o mantenerlos en la alienación» (Freire, 1970/2012, p. 71). «Cuanto más se problematizan los educandos, como seres en el mundo y con el mundo, se sentirán mayormente desafiados» (Freire, 1970/ 2012, p. 74).

En el interés de crear condiciones que apunten a un mundo donde quepan todos y todas, donde los sujetos puedan ser precisamente eso, sujetos, y no objetos, de un verdadero desarrollo humano local, encontramos la necesidad de una pedagogía crítica que visibilice la opresión, la injusticia, desestabilice los discursos de la ideología dominante y transforme la realidad abriendo caminos que conduzcan hacia la libertad, hacia la justicia.

Rechazando una práctica educativa basada en la ideología neoliberal, esta pedagogía crítica, problematizadora, del oprimido niega cualquier educación que solo responda a las necesidades del mercado.

La educación neoliberal, lejos de ser educación, como señala Freire, es «palabrería»; no tiende a la inserción crítica del educando en su realidad, sino a la acumulación cuantitativa de contenidos; es una educación bancaria.

La educación «es praxis, que implica la acción y la reflexión de los hombres sobre el mundo para transformarlo» (Freire, 1970/2012, p. 71) Se basa en una teoría del quehacer para afirmar su práctica transformadora:

Los hombres son seres de praxis, son seres del quehacer.Los hombres, como seres del quehacer, «emergen» del mundo y objetivándolo pueden conocerlo y transformarlo con su trabajo. Si los hombres son seres del quehacer, esto se debe a que su hacer es acción y reflexión. Es praxis. Es transformación del mundo. Y, por ello mismo, todo hacer del quehacer debe tener, necesariamente, una teoría que lo ilumine. El quehacer es teoría y práctica. Es reflexión y acción. No puede reducirse ni al verbalismo ni al activismo. (Freire, 1970/2012, p. 127)

Se otorga así valor a la práctica, al conocimiento impuro que se genera en las periferias, en los colectivos oprimidos, acallados por no tener el discurso de especialistas, que solo pertenece a la élite. El conocimiento de la realidad no puede estar fundado únicamente en teorías que se elaboran en lugares apartados de la realidad y por personas concretas; el conocimiento es colectivo y se funda en una relación indisoluble entre teoría y práctica. Esta argumentación viene a dar a los colectivos oprimidos, que han sido relegados de la construcción social hegemónica, la voz para eso, para ser escuchados y participar en la construcción de una sociedad en la que todos y todas vivimos y, por lo tanto, participamos, para encabezar un verdadero desarrollo humano local. 
La lectura crítica del mundo es un quehacer pedagógico político indivisible del quehacer político-pedagógico, es decir, de la acción política que envuelve la organización de los grupos y de las clases populares para intervenir en la reinvención de la sociedad. (Freire, 2001, p. 53)

Necesaria es, por tanto, una reinvención de la sociedad, una reinvención de la educación, una reinvención de los derechos humanos, tal y como señalan Freire y Herrera Flores, para que podamos transitar a otra realidad posible, a una realidad en la que merezca la pena vivir, conformándonos como «sujetos históricos que luchan por otra voluntad diferente: la de cambiar el mundo, sin que importe que esta lucha dure un tiempo tan prolongado que, a veces, sucumban en ella generaciones enteras» (Freire, 2001, p. 71).

Parece imposible un cambio de la realidad que vivimos, dado el discurso hegemónico de que no hay alternativas. La esperanza, constitutiva del ser humano, que alberga en su etimología los conceptos de espera y confianza, conduce precisamente a la confianza en lograr algo (Bouché, 2004). Es en la espera que debemos tener la constancia de continuar el camino, de dar pasos guiados por una utopía liberadora.

Al hablar de utopías puede parecer que estamos hablando de algo irrealizable, ideal, pero cualquier futuro imaginado, cualquier cosa que actualmente no supone un hecho es utopía, lo que no quiere decir que con el tiempo no se haga realidad.

Por tanto, una sociedad más igualitaria, una educación que deje de estar al servicio del mercado y se alce como una educación para la liberación del individuo, un desarrollo humano local son posibles si seguimos dando pasos. Para ello es necesario desestabilizar la realidad que pretendemos cambiar.

Es posible caminar hacia esa educación liberadora, hacia esa pedagogía de la indignación, esperanzadora, con el objetivo de que los educandos asuman una inserción crítica de la realidad en la que viven, puedan tomar las riendas de sus vidas, visibilizar la opresión, desestabilizar los discursos que los mantienen oprimidos y transformar una realidad que sea para todas y todos. Este camino no puede ser abandonado, no podemos concebir una educación reproductora de la ideología dominante y opresora de aquellos que no le son funcionales. «No importa en qué sociedad estemos ni a qué sociedad pertenezcamos; urge luchar con esperanza y denuedo» (Bouché, p. 146)

En esta reinvención del mundo, de la educación, que nos propone Freire, de los derechos humanos, que nos propone Herrera Flores, donde queremos detenernos antes de finalizar. Concretamente, en el concepto de riqueza humana que este último señala como criterio que permite afirmar o negar la generalidad de un derecho, de una teoría o de una práctica social. Se trata de que individuos, grupos, culturas desplieguen las capacidades y construyan las condiciones para conseguir la reinvención, la transformación social, un verdadero desarrollo humano local. (Herrera Flores, 2008). «Desde la 
riqueza humana se rechaza cualquier universalismo a priori que imponga criterios como si fueran el patrón oro de la idea de humanidad» (Herrera Flores, 2008, p. 180).

Estamos ante un criterio formal que hay que rellenar de contenido en el proceso de construcción de las condiciones sociales, económicas, políticas y culturales que nos permitan luchar contra los procesos que nos impiden acceder igualitariamente a los bienes materiales e inmateriales. (Herrera Flores, 2008, p. 181)

En la tarea de una práctica pedagógica crítica, problematizadora, del oprimido que nos propone Freire, encontramos las bases para proponer el criterio de riqueza humana que señala Herrera Flores, quien plantea tres tareas básicas para construir la práctica de los derechos humanos con base en ese criterio (Herrera Flores, 2008):

1. tarea: Construir el espacio público a partir de una concepción participativa de la democracia. Es esa concienciación de los sujetos que Freire nos proponía, el cambio de percepción del mundo por parte de los oprimidos.

2. a tarea: Recuperar o apropiarnos del centro de gravedad de la acción política. En esa toma de conciencia de los oprimidos, en los que estos revisan la memoria, desestabilizan los discursos, se inicia su lucha utópica en la construcción del mundo.

3. a tarea: Recuperar la conciencia de límite, de la frontera, del horizonte. La recuperación de «nuestra voluntad de poder» es el cambio de percepción del oprimido, de objeto a sujeto de conocimiento y reinvención del mundo.

El sistema educativo forma parte de la sociedad, entendida como un sistema más amplio en el que se inserta. Por tanto, la educación solo será transformada cuando la sociedad también lo haga.

Toda transformación radical y profunda de un sistema educativo solo puede producirse cuando la sociedad misma se encuentra también radicalmente transformada. (Freire, 2001, p. 168)

\section{Conclusiones}

Vivimos en un contexto conformado según las premisas de una ideología hegemónica, una ideología que no concibe más que la acumulación de riqueza como principio vertebrador de todas las acciones que le dan sentido. Para tal fin ha desarrollado una táctica global, en la que los valores que la sustentan han conseguido fraguar en todos los 
ámbitos sociales los mecanismos que la hacen continuar en su empresa. Una de las instituciones sociales que sirven de forma más eficaz al neoliberalismo es la escuela, cuya tarea resulta imprescindible: moldear sujetos que continúen reproduciendo el sistema hegemónico. Así la educación se desvirtúa en su función de crear condiciones para que los sujetos, los ciudadanos y ciudadanas, puedan tener una actitud crítica ante tal despropósito. Nos conformamos como sujetos-objetos cuyas mentes moldear y cuyas vidas programar para la perpetuación de la ideología neoliberal, para lo que se crean situaciones sociales de injusticia y opresión.

Como señalamos en la introducción, esta reflexión nace del trabajo realizado en el barrio del Polígono Sur de la ciudad de Sevilla. Comprender cómo los mecanismos de los que dispone el modelo hegemónico neoliberal afectan de manera directa la realidad de un barrio en situación de exclusión social ha permitido realizar este trabajo de investigación bibliográfica como punto de partida teórico que sirva para analizar los modelos latinoamericanos concretos. Siempre partimos de la base de que, aunque los derechos humanos son productos culturales, como afirma Herrera, discuten con una hegemonía globalizadora, con lo que afectan a un modelo educativo que, aunque tenga sus propias apropiaciones culturales, responderá a las necesidades de un modelo global en cualquier territorio del planeta.

Por este motivo, el presente artículo no versa sobre un estudio de caso, sino que se conforma como un análisis teórico que parte del modelo hegemónico global de desarrollo y examina cómo este afecta los diferentes modelos educativos.

Este modelo de desarrollo hegemónico establece que el valor de las cosas y de las personas viene dado por su valor de cambio, por su capacidad de acumulación de capital, y no por el valor de uso, por su utilidad. Por tanto, se torna realmente difícil el acceso a una ciudadanía más allá de su condición como consumidora de bienes y servicios.

Los individuos son confinados a una posición de meros espectadores de la realidad social de sus territorios, que parece funcionar como la única opción posible. Con su fin de la historia, la utopía conservadora del neoliberalismo legitima el funcionamiento social territorial, en el que hasta el propio territorio parece no cuestionar su sumisión a los intereses del mercado. Secuestrados por este, los territorios invierten su papel como garantes de la vida social para ser garantes de la economía neoliberal.

La reducción de la participación social en los procesos territoriales es fundamental para la supervivencia de una hegemonía que representa los valores de competitividad, acumulación, individualismo, y va desplazando los valores de solidaridad, cooperación y colectivismo que han permitido la existencia humana hasta nuestros días.

El sistema educativo, como institución encargada de la reproducción social, parece ser el lugar idóneo donde perpetuar cualquier ideología. Las personas pasan los primeros años de vida metidas en instituciones escolares que las conforman bajo un tipo ideal de sujeto. Desvirtuando la función social de la educación como posibilitadora de un 
pensamiento reflexivo que sitúe al individuo en una posición crítica ante la realidad en que se encuentra, el sistema educativo convierte a esta en una herramienta con la que moldear individuos que hagan funcionar la maquinaria capitalista.

Las diferencias de clases son así también reproducidas dentro de la escuela, asegurando de esta forma una homogeneidad que mantenga la estructura social de los territorios. Las jerarquizaciones en las relaciones se dan en cuanto el profesorado posee los conocimientos y el alumnado, que no sabe nada, debe ser llenado de todos los contenidos que establece un conocimiento especializado. Se enseña en la escuela a no cuestionar, a asumir los conceptos tal como nos llegan, a naturalizar un orden social injusto en el que una élite está especializada para hacer que el mundo funcione.

Ante esta situación se hace necesario un cambio de paradigma en la concepción de la educación dentro del sistema educativo actual que aborde los procesos de desarrollo local, desestabilizar el discurso dominante que configura la sociedad y a sus instituciones en los procesos territoriales.

De los contextos en los que las desigualdades sociales visibilizan aún más un modo social injusto es desde donde debemos partir para recuperar una educación que sirva para la liberación del ser humano, iniciando procesos de emancipación social y humana, de un verdadero desarrollo humano local.

Para ello es necesaria una reinvención de los procesos de desarrollo local, una reinvención de la educación, una reinvención de los derechos humanos, que ponga en evidencia el discurso de no hay alternativas que la ideología dominante ha fraguado en nuestras consciencias. Así podremos comenzar a dar pasos hacia la liberación del ser humano para que este, con una inserción crítica en la realidad en que vive, visibilice la opresión, desestabilice los discursos que lo mantienen oprimido y transforme una realidad para todas y todos.

Crear prácticas educativas contrahegemónicas que lleven a esa reinvención de la educación y de la sociedad parece ser el punto de partida en contextos en los que los oprimidos puedan construir procesos de desarrollo humano local que promuevan la salida de la situación de exclusión en la que se encuentran.

\section{Referencias bibliográficas}

ANEP (2000). Una visión integral del proceso de reforma educativa en Uruguay 19951999. Montevideo: ANEP.

Apple, M. (1997). Teoría crítica y educación. Buenos Aires: Miño y Dávila.

Autés, M. (2004). La exclusión social: Bordeando sus fronteras. Definiciones y matices. Barcelona: Gedisa. 
Berger, S. (2006). La producción cultural en escuelas en contexto de pobreza urbana. Anuario Digital de Investigación Educativa, 17. Recuperado de http:/ / revistas.bibdigital.uccor.edu.ar/ index.php/ adiv/ article/ view/ 3309.

Bouché, J. (2004). Educar para un nuevo espacio humano. Madrid: Dykinson.

Bourdieu, P. (2001). La reproducción: Elementos para una teoría del sistema de enseñanza. Madrid: Popular.

Dubois, A.y Del Río, A. (2014). Marco teórico y metodológico del desarrollo humano local: Versión abreviada. Bilbao: Universidad del País Vasco.

Durkheim, E. (1975). Educación y sociología. Barcelona: Península.

Escudero, J. M. (2002). La reforma de la reforma ¿Qué calidad para quiénes? Barcelona: Ariel.

Freire, P. (1990). La naturaleza política de la educación: Cultura, poder y liberación. Barcelona: Paidós.

Freire, P. (2001). Pedagogía de la indignación. Madrid: Morata.

Freire, P. (2009). La educación como práctica de la libertad. Madrid: Siglo XXI.

Freire, P. (2012). Pedagogía del oprimido. Madrid: Siglo XXI

Gallicchio, E. (2010). ¿El desarrollo local está de moda? Universitas Forum, 2(1).

Harvey, D. (2007). Breve historia del neoliberalismo. Madrid: Akal.

Herrera Flores, J. (2008). La reinvención de los derechos humanos. Sevilla: Atrapasueños. Jiménez, M., Luengo,J.y Taberner,J. (2009). Exclusión social y exclusión educativa como fracasos: Conceptos y líneas para su comprensión e investigación. Profesorado: Revista de Currículum y Formación del Profesorado, 13(3), 11-49.

López, L. y Taberner, J. (2009). La comunidad educativa ante los resultados escolares. Barcelona: Milrazones.

Martinis, P. (2006). Educación, pobreza e igualdad: Del niño carente al sujeto de la educación. En P. Martinis y P. Redondo (comps). Igualdad y educación escrituras (entre) dos orillas (pp. 13-31). Buenos Aires: Del Estante.

Organizaciones de las Naciones Unidas. Comité de Derechos Económicos, Sociales y Culturales. (2000). Informe sobre los períodos de sesiones 20. y 21. o. Suplemento 2. Nueva York: ONU.

Samour, H. (1994). Crítica radical al neoliberalismo. Estudios Centroamericanos ECA, 49(552), 1069-1101.

Santos, B. de Sousa. (1998). Una concepción multicultural de los derechos humanos. Utopías, Nuestra Bandera: Revista De Debate Político, 178, 91-106.

Tezanos, J. F. (2001). Tendencias en desigualdad y exclusión social: Tercer foro sobre tendencias sociales. Madrid: Sistema.

Torres, J. (2001). Educación en tiempos de neoliberalismo. Madrid: Morata. 